inations did not differ significantly for the two levels of deprivation. The mean number of errors was significantly $(p<.05)$ different over the three levels of time spent under deprivation. Time by deprivation level differences were not significant.

Table 1

Analysis of Variance for Time by Deprivation Level

\begin{tabular}{lrrc}
\hline Source & df & MS & F \\
\hline Deprivation Level & 1 & 6.000 & .79 \\
Time & 2 & 27.125 & $3.57^{*}$ \\
DL by T & 2 & 7.625 & .29 \\
Within & 18 & 28.361 & \\
Total & 23 & & \\
\hline
\end{tabular}

$* p<.05$

Experimental Ss under 15- and 60-min conditions made fewer mean errors to a learning criterion than did Ss in corresponding control groups. Experimental Ss in the 30 -min group made more mean errors than 30 -min control Ss.

Table 2

Mean Errors on Visual Discrimination Task

\begin{tabular}{ccc}
\hline Time & Experimental Group & Control Group \\
\hline 15 & 7.00 & 9.00 \\
30 & 8.50 & 7.25 \\
60 & 10.00 & 12.25 \\
\hline
\end{tabular}

\section{DISCUSSION}

For increased deprivation times mean errors to a visual discrimination-learning criterion decreased significantly $(p<.05)$ in the present study. However, the relationship between deprivation time and discrimination error production was reversed in the 30 -min groups as compared to the 15 - and 60 -min groups. This may have been due to increased perception of internal stimuli in the 30 -min sensory-deprivation group, and increased self-stimulating acuity leading to no increased external stimulation needs during subsequent testing on a visual discrimination task. Whereas the 15-min group was sensorially deprived, results based upon discrimination errors indicated the 30-min group may merely have substituted internal for external stimulus factors. Under the disorienting effect of 60 -min sensory deprivation this substitution process ceased and $\mathrm{Ss}$ were again under sensory deprivation. The qualitative difference of the $30-\mathrm{min}$ group so reversed error scores as to preclude differential SD by Time interactions. These results suggest that the internal tension build-up Goldfried (1960) hypothesized may be the result of the disorienting effects of certain sensory deprivation periods rather than general lack of external stimulation.

The results failed to support the hypothesis that higher levels of sensory deprivation would increase rates of learning on a visual discrimination problem but

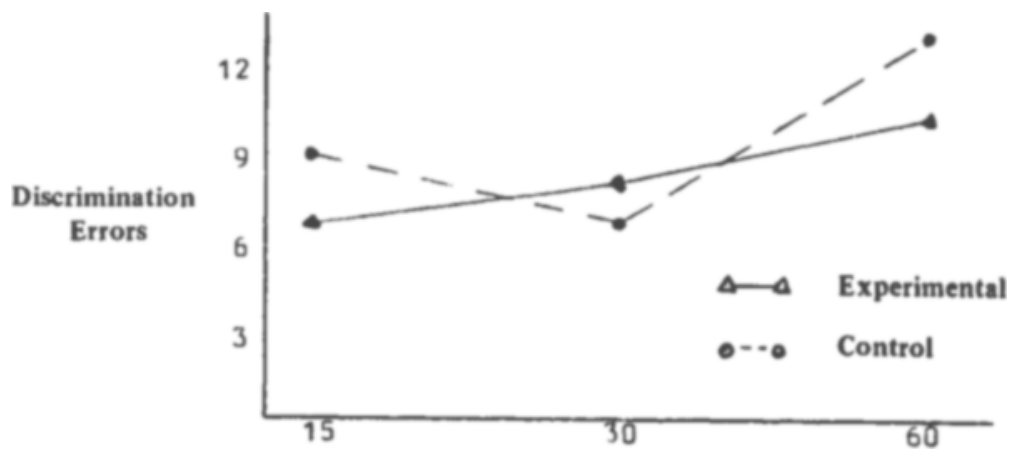

Fig. 2. Plot of mean visual discrimination errors.

supported the hypothesis that total time spent in deprivation, whether of a mild social isolation nature or severe sensory nature, would have a significant $(\mathrm{p}<.05)$ effect upon learning a visual discrimination task. Further investigation as to whether error reduction was due to actual visual discrimination improvement or increased interest factors is clearly indicated, as well as further exploration of the acclimation process involved in sensory deprivation. REFERENCES

GOLDFRIED, M. A psy choanaly tic interpretation of sensory deprivation. Psychological Record, $1960,10,211-214$

KENDLER, H. H., \& KENDLER, T. S. Vertical and horizontal processes in problem solving. Psychological Review, 1962, 1-16.
ROBERTSON, M., \& WALTER, D. The effect of sensory deprivation upon scores on the Wechser Adult Intelligence Scale. Journal of Psychology, 1963, 56, 213-218.

SCOTT, T., BEXTON, W., HERON, W., \& DOANE, B. Cognitive effects of perceptual isolation. Canadian Journal of Psychology, $1959,13,200-209$.

VERNON, J., \& MCGILL, T. The effect of sensory deprivation upon rote learning. American Journal of Psychology, 1957, 70,637-639.

VERNON, J., \& MCGILL, T. Utilization of visual stimulation during sensory deprivation. Perceptual \& Motor Skills, 1960, 11, 214-221.

WINER, B. Statistical principles in experimental design. New York: McGraw-Hill, 1962

ZUCKERMAN, M., \& HABER, M. Need for stimulation as a source of stress response to perceptual isolation. Journal of Abnormal Psychology, 1965, 70, 371-377.

\title{
Adaptation of the wrist to displacing prisms
}

ALLAN H. PUTTERMAN, ANDREW L. ROBERT, and ALBERT S. BREGMAN, McGill University, Montreal 110, Canada

Tests were carried out to determine whether or not Harris' position sense theory holds true for the hand in relation to the arm and whether or not there occurs $a$ spontaneous change in the position sense of the arm due to (possible) adaptation in the hand. Eight Ss adapted to displaced vision by pointing to a moveable target while wearing displacing prisms. During this adaptation period, $\mathrm{Ss}$ ' arms were immobilized, but their wrists were free to move. During testing, Ss were told to use the entire forearm in pointing to the target. Control Ss, not subjected to displaced vision, were required to point to the target with the entire forearm. Results showed that the position sense of the hand does indeed change during adaptation, but transfer of this adaptation to the forearm does not occur. 
Much of the research that has been carried on in the field of perceptual-motor adaptation recently has concerned itself with the theories of Charles Harris (e.g., Rock \& Harris, 1967). Briefly, Harris sees motor adaptation to be a change in the position sense of the limb involved (e.g., arm), rather than a change in visual perception. The term "position sense" refers to the felt position of the arm as dictated by the proprioceptive feedback from the muscles, joints, etc. Harris (1965) has provided evidence in support of this theory. However, most of the experiments thus far conducted have used the arm as a whole. The purpose of the following experiment was to determine whether or not this position sense theory holds true for the hand in relation to the arm as it has been shown to do for the arm in relation to the rest of the body. Secondly, it was to determine whether or not there occurs a spontaneous transfer of adaptation from the hand to the forearm, when the latter has been held immobile during adaptation.

\section{METHOD}

The experimental group consisted of eight Ss of college age. Each S was seated at a table and was fitted with apparatus which immobilized his right index finger. A pointer was attached to the tip of the index finger. Thus, the S's hand, index finger, and the pointer consistuted one inflexible unit which was hinged at the wrist. The right forearm was taped to the surface of the table, rendering it immobile for the duration of the adaptation period.

The adaptation period was conducted as follows: The entire forearm and pointer were hidden from view of the $S$ by means of a covered sheet of Plexiglas, supported above the S's arm. The S's chin was placed on a supporting cup to immobilize his head. This was done to prevent adaptation from occurring by means of a change in the position sense of the head. A laterally displacing prism (attached to goggles) was then placed over the S's left eye, his right eye being covered. The angle of displacement was $23 \mathrm{deg}$, with the base to the right.

The $\mathrm{S}$ was then asked to point to a target whose position was randomly changed (within a range of $24 \mathrm{in}$.) with each trial. After pointing, the $S$ was permitted to see the position of the pointer and to make the necessary adjustment. In this way, adaptation was effected after a short number of trials. The criterion for adaptation was maximum accuracy (i.e., to the nearest .25 in.) on three consecutive trials. When this criterion was achieved, the testing trials were begun.

In the test period the displacing prism was taken off and the binding tape was removed from the forearm. The $S$ was then told to

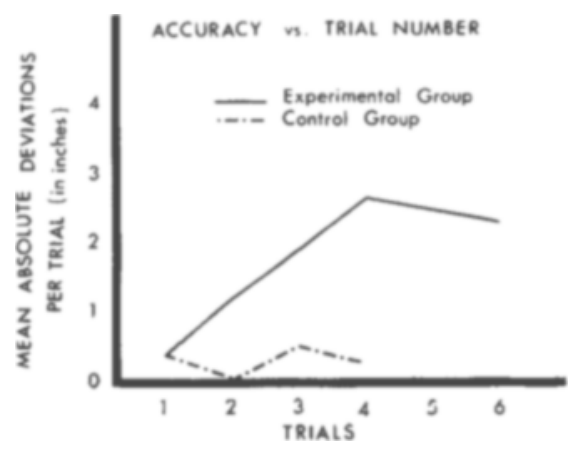

Fig. 1. Accuracy vs trial number during testing.

straighten his hand in relation to his forearm. This instruction was repeated on every second trial of the test period. The S was instructed to use his entire forearm in pointing to the target, using his elbow as a pivot point. Again the target was repositioned after each trial, but this time no visual feedback was provided. Therefore, the $S$ was not aware of the extent of his accuracy. Measurements were taken of the distance between the points where the tip of the pointer and the center of the target touched the scale. Six test trials were conducted with each $S$. The test procedure was then administered to a control group of eight Ss who had not been subjected to the adaptation procedure, i.e., they never wore the displacing prism. Their deviations from the target were also recorded. This time only four test trials were conducted with each $S$. A statistical comparison was then made of the mean deviations of the two groups. RESULTS

The results of the experimental and control groups on the six test trials are presented in Fig. 1. These measurements were made by noting the position of the tip

\section{WRIST POSITION DURING TESTING}

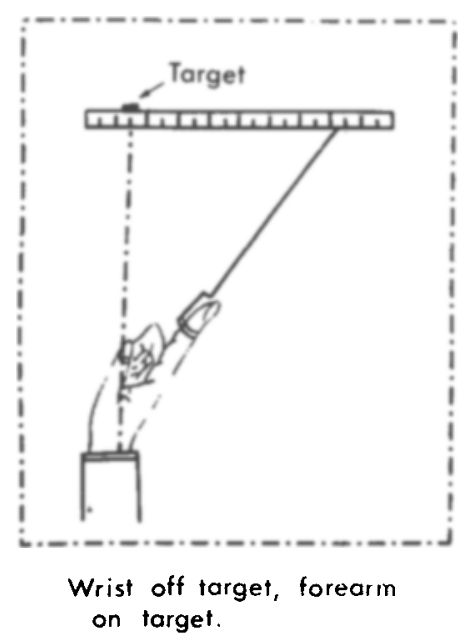

Fig. 2. Wrist position during testing. of the pointer on a scale running linearly along both sides of the target perpendicular to a line drawn straight ahead from the wrist (see Fig. 1). The straight line between the S's elbow and wrist, extended, was consistently on target. This was determined by visual sightings along this axis. Deviations resulted from a bending of the wrist, the forearm itself still being on target (see Fig. 2). It is to be noted that the experimental Ss were consistently accurate on their first trials. On subsequent trials, however, their accuracy decreased. This radical change was not to be found in the control group (see Fig. 2). The mean absolute deviation of the control group was .227 in.

The mean absolute deviations of the first four experimental group trials were each compared to the deviation of the corresponding control group trial, and the differences in Trials 2 to 4 were found to be statistically significant [i.e., $t(1)=0$, not significant; $\mathrm{t}(2)=2.419, \mathrm{p}<.05$; $\mathrm{t}(3)=3.929, \mathrm{p}<.01 ; \mathrm{t}(4)=10.716$, $\mathrm{p}<.001 ; \mathrm{df}=14$ in all cases] .

\section{DISCUSSION}

The results of this experiment are quite conclusive. (a) It was the position sense of the hand in relation to the arm that changed during the adaptation period. This was shown by the fact that Ss, although told repeatedly to keep their wrists straight throughout the testing period, actually kept them bent, believing that they were straight (except during the first trial). (b) There was no spontaneous transfer of the adaptation to the forearm. This was demonstrated by the fact that Ss' pointing ability with the forearm remained unaltered.

We would now explain the interesting observation that the experimental Ss did straighten their wrists when first told to do so, but later could not. The ability to keep the wrist straight had been completely mastered by $\mathrm{Ss}$ previous to their confronting the experimental situation. On the other hand, the learning achieved in the experiment was entirely new, and also specific to that situation. Between the adaptation and testing sessions, there was a period of time during which Ss rested, moved their arms and wrists about, etc. Thus, when told to straighten their wrists for the first time, the novelty of the situation allowed the prior ability to manifest itself. However, as Ss became more deeply involved with the task at hand-under the influence of the associated specific stimuli-they once more displayed the newly learned form of behavior.

\section{REFERENCES}

HARRIS, C. S. Perceptual adaptation to inverted, reversed, and displaced vision. Psychological Review, 1965, 72, 419.444.

ROCK, I., \& HARRIS, C. S. Vision and touch. Scientific American, 1967, 216, 96-104. 